Research Paper

\title{
Whey Protein Improves Marathon-Induced Injury and Exercise Performance in Elite Track Runners
}

\author{
Wen-Ching Huang, 1 Y ung-Cheng Chang2, Yi-Ming Chen³, Yi-Ju Hsu³, Chi-Chang Huang', Nai-Wen \\ $\mathrm{Kan}^{4 凶}$, Sheng-Shih Chen ${ }^{\mathrm{\varpi}}$ \\ 1. Department of Exercise and Health Science, National Taipei University of Nursing and Health Sciences, Taipei 11219, Taiwan; \\ 2. Department of Sports Training Science-Athletics, National Taiwan Sport University, Taoyuan 33301, Taiwan; \\ 3. Graduate Institute of Sports Science, National Taiwan Sport University, Taoyuan 33301, Taiwan; \\ 4. Center for General Education, Taipei Medical University, Taipei 11031, Taiwan; \\ 5. Department of General Surgery, Kaohsiung Veterans General Hospital, Kaohsiung 81362, Taiwan. \\ $\square$ Corresponding authors \\ (c) Ivyspring International Publisher. This is an open access article distributed under the terms of the Creative Commons Attribution (CC BY-NC) license \\ (https://creativecommons.org/licenses/by-nc/4.0/). See http://ivyspring.com/terms for full terms and conditions.
}

Received: 2017.02.09; Accepted: 2017.04.17; Published: 2017.06.22

\begin{abstract}
Whey protein has been widely applied to athletes and the fitness field for muscle growth and performance improvement. Limited studies focused on the beneficial effects of whey on aerobic exercise according to biochemical assessments. In the current study, 12 elite male track runners were randomly assigned to whey and maltodextrin groups for 5 weeks' supplementation. The aim of this study was to investigate the effect of whey protein on physiological adaptions and exercise performance. During this period, three time points (pre-, post-, and end-test) were used to evaluate related biochemical parameters, body composition, and performance. The post-test was set 1 day after a marathon for injury status evaluation and the end-test was also assessed after 1 -week recovery from endurance test. The results showed that the whey group exhibited significantly lower aspartate aminotransferase, alanine aminotransferase, lactate dehydrogenase, and creatine kinase indicators after the marathon (post-test), as well as at the end-test $(p<0.016)$. The endurance performance in twelve-minute walk/run was also significantly elevated $(p<0.012)$ possibly due to an increase in the muscle mass and amelioration of exercise injuries. In the current study, we demonstrated that whey protein can also be used for aerobic exercise for better physiological adaptation, in addition to resistance training. Whey protein could be also a potential nutrient supplement with a variety of benefits for amateur runners.
\end{abstract}

Key words: whey protein, aerobic exercise, running, clinical biochemistry, performance.

\section{Introduction}

Whey protein, the byproduct of casein precipitation during cheese manufacturing, contains valuable food ingredients, such as (in order of abundance) alpha-lactoglobulin, beta-lactalbumin, immunoglobulins, bovine serum albumin, lactoferrin, lactoperoxidase, phospholipoprotein, bioactive factors, and enzymes [1], with nutritional value and functional bioactivities. Whey protein supplementation is widely applied for strength-trained athletes with the intent to improve muscle mass and quality [2]. Whey protein isolates contain high amounts of branched-chain amino acids (essential amino acids), and the high leucine content in whey protein can stimulate muscle protein synthesis [3] and elevate mammalian target of rapamycin (mTOR) signaling activation [4]. Resistance training, regardless of the contraction mode, can also contribute to muscle hypertrophy and adaptation with whey supplementation [5]. In the fitness market, whey protein is considered a priority supplement for muscle development when combined with resistance training. Many studies focused on whey supplementation combined with resistance exercise in different spectra [6]. Therefore, there are quite a few studies that focused on the beneficial effects of whey protein on aerobic training in terms of 
physiological adaptation.

High-intensity workouts, exercise training, and sports competitions impact the body's hemostasis, with resulting pathological syndromes. Physiological functions of important tissues are affected by long-term, high-intensity exercise that may exceed the body's endurance [7]. Several clinical biochemical parameters considered biomarkers for evaluating physiological functions or status after exercise or training include aspartate aminotransferase (AST), alanine aminotransferase (ALT), lactate dehydrogenase (LDH), and creatine kinase (CK) $[8,9]$. The metabolic index, such as blood urea nitrogen (BUN), can be used to evaluate the metabolic status, and biomarkers, including blood urea nitrogen (BUN), LDH, CK, AST, and ALT, can also be applied to assess physiological fatigue and recovery $[10,11]$.

In our previous study of animal experimental observations, we elucidated that whey protein can significantly mitigate the increase of physiological biomarkers induced by intensive aerobic training and improve exercise performance [12]. In the current clinical trial, we wanted to elucidate the beneficial effects of whey on highly intensive training of an aerobic exercise type for translational research purposes. Whey protein supplementation may be helpful to athletes who focus on muscle building or performing aerobic exercise such as marathons, long-distance cycling, and swimming as well as for overall physiologic protective effects.

\section{Methods}

\section{Experimental design}

A randomized, double-blind study was used to compare the effects of consuming whey protein vs. maltodextrin (a placebo) on National Taiwan Sport University (NTSU) male track team elite athletes. In Figure 1, each groups $(n=6)$ was administrated whey protein (EAS 100\% WP, vanilla) or the placebo at 33.5 g/day with equal caloric (130.5 kcal) contents after their daily programmed training protocol for 5 consecutive weeks (Fig. 1). Participants in both groups were received the whey protein or placebo drink within $30 \mathrm{~min}$ after daily training protocol. There were three assessment points (pre-test, post-test, and end-test) to evaluate the beneficial effects on biochemistry, exercise performance, and body composition. The post-test was arranged 1 day after a marathon competition to understand the physiological status. The programmed training prescriptions were maintained for the duration of the study.

\section{Subjects}

Twelve male university athletes from the track team volunteered to participate in this study. Subjects were not allowed to participate in this study if they had any metabolic disorders including known metabolic disorders, heart/cardiopulmonary diseases, diabetes, thyroid disease, hypogonadism, hepatorenal disease, musculoskeletal disorders, neuromuscular/neurological diseases, autoimmune diseases, cancer, peptic ulcers, or anemia. All subjects provided written informed consent before participation. The study was reviewed and approved by the Joint Institutional Review Board of Taipei Medical Hospital (Taipei, Taiwan; TMU-JIRB no. 201302021). Subjects were asked to keep their normal dietary pattern, and their daily caloric intake was recorded by dietitians during the experimental period. Other nutrients including types of protein, antioxidants, creatine, and steroid supplementation were also forbidden. Subjects were randomly assigned to the whey protein or placebo group, and the basic characteristics of age $(21.7 \pm 2.7$ vs. $21.0 \pm 2.0$ years), height (176.2 \pm 2.6 vs. $177 \pm 2.6 \mathrm{~cm})$, and weight $(61.6 \pm 3.4$ vs. $63.2 \pm 3.7 \mathrm{~kg})$ did not significantly differ before the experiment.

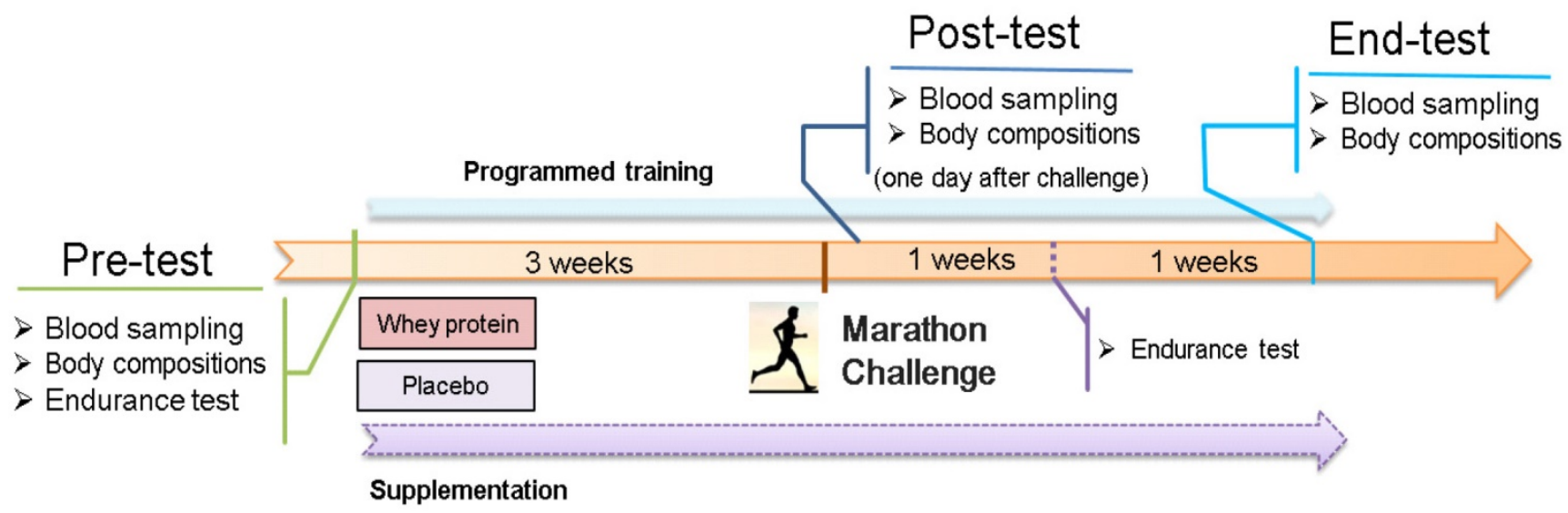

Figure 1. Experimental design. Whey protein or a placebo (maltodextrin) was administrated with an isocaloric content after daily training. The 5-week experimental duration contained three time point assessments for biochemistry, body composition, and exercise performance. 


\section{Clinical biochemistry}

Blood samples (serum) were taken at the indicated three time points after subjects had fasted for at least $8 \mathrm{~h}$ for the biochemical assessments. Clinical biochemical assessments of levels of AST, ALT, alkaline phosphatase (ALP), LDH, CK, total bilirubin (TBIL), total protein (TP), BUN, uric acid (UA), total cholesterol (TC), triacylglycerol (TG), high-density lipoprotein (HDL), and low-density lipoprotein (LDL) involved use of an autoanalyzer (Hitachi 7060; Tokyo, Japan).

\section{Anthropometric measurements}

All subjects arrived at the laboratory in the morning for anthropometric measurements including body height $(\mathrm{cm})$, body mass $(\mathrm{kg})$, body fat percentage (\%), skeletal muscle mass (SMM, kg), and body-mass index (BMI; $\mathrm{kg} / \mathrm{m}^{2}$ ). Standing body height without shoes or socks was measured to the nearest $0.1 \mathrm{~cm}$ with a height meter mounted on a wall. Body mass, body fat, and muscular weight were measured by a bioelectrical impedance instrument (InBody 720, Biospace, Seoul, Korea) with standard methods to assess the body composition.

\section{Twelve-minute walk/run performance}

A single 12-min walk/run test was performed. Before the test, sufficient dynamic warm-up was required. Each subject was encouraged to give his best effort-to walk and/or run to cover as much distance as possible in $12 \mathrm{~min}$. The distance of each individual was consecutively measured and recorded at 3, 6, 9, and $12 \mathrm{~min}$ into the walk/run test as an endurance performance reference.

\section{Statistical analysis}

Statistical analyses were performed using SPSS version 18.0 software (SPSS, Chicago, IL, USA). Data are expressed as the mean $\pm \mathrm{SD}$. A mixed design two-way analysis of variance (ANOVA) (supplementation $\mathrm{x}$ time) was used to compare the variables of biochemistry, body compositions, and exercise performance. Data were considered statistically significant when the probability of a type I error was $<0.05$. A post-hoc independent-repeated $t$-test was used to compare subjects' characteristics between the groups when the main effect or interaction effect was significant. Significance $\left(^{*}\right)$ was set at an alpha level of $0.016(0.05 / 3)$ for biochemical parameters and body composition or at 0.0125 $(0.05 / 4)$ for exercise performance.

\section{Results}

\section{Effects of supplements on biochemical variables profiles}

Biochemical results at the indicated points of the experiment can provide clinical information about the physiological adaptation status of subjects. In this part, we categorized different parameters according to physiological functions (Table 1). Both hepatic indexes, AST and ALT, showed significant supplementation main effects $(\mathrm{F}(1,10)=16.8, p=0.002$; $\mathrm{F}(1,10)=35.7, p<0.001$, respectively) and interaction effects $(\mathrm{F}(2,20)=9.85, p=0.001 ; \mathrm{F}(2,20)=4.19, p=0.03$, respectively). Only AST had a significant time main effect $(F(2,20)=24.54, p=0.03)$, and the whey group did not exhibit a significant AST increase from oxidation-induced liver pressure $(p>0.016)$ compared to the placebo group at the post-test after the marathon. Both AST and ALT significantly decreased in the whey group compared to the placebo group $(p<0.016)$, and the end-test point also showed a similar significance in AST levels $(p<0.016)$.

For the LDH and CK injury indexes, the statistical analysis demonstrated significant supplementation main effects $(\mathrm{F}(1,10)=21.64, p=0.001$; $\mathrm{F}(1,10)=39.96, p<0.001$, respectively), time main effects $(\mathrm{F}(2,20)=5.99, \quad p=0.009 ; \quad \mathrm{F}(2,20)=57.96, \quad p<0.001$, respectively), and interaction effects $(\mathrm{F}(2,20)=5.09$, $p=0.016 ; \mathrm{F}(2,20)=23.56, p<0.001$, respectively). After the marathon challenge (post-test), $\mathrm{LDH}$ and $\mathrm{CK}$ levels in the placebo group significantly increased $(p<0.016)$ but not in the whey group. Both LDH and CK of the whey group also exhibited significant decreases compared to the placebo group at the post-test and end-test points $(p<0.016)$.

As to lipid-related parameters, TG and TC showed significant supplementation main effects $(\mathrm{F}(1,10)=5.59, \quad p=0.04 ; \quad \mathrm{F}(1,10)=9.46, \quad p=0.012$, respectively) and time main effects $(\mathrm{F}(2,20)=25.63$, $p<0.001 ; \mathrm{F}(2,20)=7.35, p=0.004$, respectively). Both groups showed significantly decreased TG levels $(p<0.016)$, and only the placebo group had significantly increased TC levels $(p<0.016)$. The whey group had significantly decreased TC and TG levels $(p<0.016)$ compared to the placebo group after the marathon challenge (post-test). LDL demonstrated significant supplementation main effects $(\mathrm{F}(1,10)=49.72, \quad p<0.001)$ and interaction effects $(F(2,20)=6.64, p=0.007)$. LDL levels of the whey group significantly decreased at the post-test and end-test points. 
Table 1. Effect of supplementation on biochemical serum profile levels at three time point assessments

\begin{tabular}{|c|c|c|c|c|c|c|c|}
\hline \multirow[t]{2}{*}{ Parameters } & \multirow[t]{2}{*}{ Treatments } & \multirow[t]{2}{*}{ Pre-test } & \multirow[t]{2}{*}{ Post-test } & \multirow[t]{2}{*}{ End-test } & \multicolumn{3}{|l|}{$p$ value } \\
\hline & & & & & $\begin{array}{l}\text { Main effect } \\
\text { (Sup.) }\end{array}$ & $\begin{array}{l}\text { Main effect } \\
\text { (Times) }\end{array}$ & $\begin{array}{l}\text { Interaction } \\
\text { (Sup. x Times) }\end{array}$ \\
\hline \multirow[t]{2}{*}{ AST (U/L) } & Placebo & $24.3 \pm 2.6^{a}$ & $43.7 \pm 11.8^{b}$ & $23.7 \pm 1.2^{a}$ & 0.002 & $<0.001$ & 0.001 \\
\hline & Whey & $24 \pm 2.1 \mathrm{ab}$ & $26 \pm 2.0^{*}, \mathrm{a}$ & $19 \pm 2.3^{*}, \mathrm{~b}$ & & & \\
\hline \multirow[t]{2}{*}{ ALT (U/L) } & Placebo & $21.5 \pm 2.7$ & $24.7 \pm 6.9$ & $22.0 \pm 1.7$ & $<0.001$ & 0.121 & 0.030 \\
\hline & Whey & $18.5 \pm 3.8$ & $17.5 \pm 1.5^{*}$ & $18.3 \pm 3.6$ & & & \\
\hline \multirow[t]{2}{*}{$\operatorname{ALP}(\mathrm{U} / \mathrm{L})$} & Placebo & $62.5 \pm 8.8$ & $60.5 \pm 10.2$ & $69.3 \pm 8.6$ & 0.703 & 0.213 & 0.817 \\
\hline & Whey & $63.7 \pm 6.3$ & $59.7 \pm 11.3$ & $67.3 \pm 9.3$ & & & \\
\hline \multirow[t]{2}{*}{ LDH (U/L) } & Placebo & $163.8 \pm 15^{a}$ & $176.8 \pm 18^{b}$ & $173 \pm 10^{\mathrm{ab}}$ & 0.001 & 0.009 & 0.016 \\
\hline & Whey & $159.2 \pm 5$ & $159.2 \pm 8^{*}$ & $153 \pm 9^{*}$ & & & \\
\hline \multirow[t]{2}{*}{ CK (U/L) } & Placebo & $141.8 \pm 42^{\mathrm{a}}$ & $545.3 \pm 122^{\mathrm{b}}$ & $253.2 \pm 39 c$ & $<0.001$ & $<0.001$ & $<0.001$ \\
\hline & Whey & $154.8 \pm 30 \mathrm{ab}$ & $232.5 \pm 55^{*, \mathrm{~b}}$ & $129.3 \pm 18^{*}, \mathrm{a}$ & & & \\
\hline \multirow[t]{2}{*}{$\operatorname{ALB}(\mathrm{g} / \mathrm{dL})$} & Placebo & $4.7 \pm 0.1$ & $4.7 \pm 0.2$ & $4.5 \pm 0.1$ & 1.000 & $<0.001$ & 0.750 \\
\hline & Whey & $4.7 \pm 0.1$ & $4.7 \pm 0.1$ & $4.5 \pm 0.2$ & & & \\
\hline \multirow[t]{2}{*}{$\mathrm{TP}(\mathrm{g} / \mathrm{dL})$} & Placebo & $6.8 \pm 0.3$ & $7.1 \pm 0.2$ & $6.9 \pm 0.2$ & 0.692 & 0.015 & 0.771 \\
\hline & Whey & $6.9 \pm 0.3$ & $7.1 \pm 0.3$ & $6.9 \pm 0.1$ & & & \\
\hline \multirow[t]{2}{*}{ BUN (mg/dL) } & Placebo & $12.9 \pm 0.6^{a}$ & $16.9 \pm 2.5^{b}$ & $16.4 \pm 2.0^{\mathrm{b}}$ & 0.001 & 0.590 & 0.001 \\
\hline & Whey & $13.9 \pm 1.6$ & $12.6 \pm 1.4^{*}$ & $11.6 \pm 0.9^{*}$ & & & \\
\hline \multirow[t]{2}{*}{ Creatine $(\mathrm{mg} / \mathrm{dL})$} & Placebo & $0.9 \pm 0.1$ & $0.8 \pm 0.1$ & $0.8 \pm 0.1$ & 0.097 & 0.428 & 0.553 \\
\hline & Whey & $0.8 \pm 0.1$ & $0.8 \pm 0.1$ & $0.8 \pm 0.1$ & & & \\
\hline \multirow[t]{2}{*}{$\mathrm{UA}(\mathrm{mg} / \mathrm{dL})$} & Placebo & $5.1 \pm 0.5$ & $5.8 \pm 0.6$ & $5.1 \pm 0.3$ & 0.214 & 0.003 & 0.778 \\
\hline & Whey & $5.4 \pm 0.6$ & $5.9 \pm 0.5$ & $5.4 \pm 0.2$ & & & \\
\hline \multirow[t]{2}{*}{ GLU (mg/dL) } & Placebo & $91.2 \pm 3$ & $88.8 \pm 3$ & $91.3 \pm 3$ & 0.243 & 0.022 & 0.100 \\
\hline & Whey & $91.2 \pm 1$ & $89.5 \pm 3$ & $92.0 \pm 3$ & & & \\
\hline \multirow[t]{2}{*}{$\mathrm{TG}(\mathrm{mg} / \mathrm{dL})$} & Placebo & $73 \pm 9^{a}$ & $65.2 \pm 15^{b}$ & $142 \pm 43^{c}$ & 0.040 & $<0.001$ & 0.158 \\
\hline & Whey & $74 \pm 7 \mathrm{a}$ & $45.3 \pm 9^{*, \mathrm{~b}}$ & $104 \pm 34^{\mathrm{b}}$ & & & \\
\hline \multirow[t]{2}{*}{$\mathrm{TC}(\mathrm{mg} / \mathrm{dL})$} & Placebo & $177 \pm 13^{a}$ & $196 \pm 13^{b}$ & $165 \pm 32^{\mathrm{ab}}$ & 0.012 & 0.004 & 0.388 \\
\hline & Whey & $173 \pm 9$ & $171 \pm 9^{*}$ & $143 \pm 22$ & & & \\
\hline \multirow[t]{2}{*}{ HDL (mg/dL) } & Placebo & $68 \pm 4$ & $75 \pm 2$ & $61 \pm 4$ & 0.945 & 0.002 & 0.303 \\
\hline & Whey & $63 \pm 7$ & $75 \pm 9$ & $65 \pm 9$ & & & \\
\hline \multirow[t]{2}{*}{ LDL (mg/dL) } & Placebo & $88 \pm 7$ & $98 \pm 18$ & $102 \pm 9$ & $<0.001$ & 0.489 & 0.007 \\
\hline & Whey & $86 \pm 5$ & $82 \pm 4^{*}$ & $76 \pm 9^{*}$ & & & \\
\hline
\end{tabular}

The post-test was assessed 1 day after the marathon. The main effect of supplementation (Sup.) means the whey and placebo treatment and the other main effect of time was the three time point assessments (pre-test, post-test, and end-test). Data are presented as the mean \pm SD for $n=6$ in each group. Statistical analysis was performed by a two-way ANOVA, and $p$ values of $<0.05$ are considered to significantly differ. The post-hoc test was performed by a repeated Student's $t$-test between groups at the same time point, and significance $\left(^{*}\right)$ was set at an alpha level of $0.016(0.05 / 3)$. Data in the same row (within group) followed by different letters $(\mathrm{a}, \mathrm{b}$, and $\mathrm{c})$ significantly differ at $p<0.016$ $(0.05 / 3)$. AST, aspartate aminotransferase; ALT, alanine aminotransferase; ALP, alkaline phosphatase; LDH, lactate dehydrogenase; CK, creatine kinase; ALB, albumin; TP, total protein; BUN, blood urea nitrogen; UA, uric acid; GLU, glucose; TG, triacylglycerol; TC, total cholesterol; HDL, high-density lipoprotein; LDL, low-density lipoprotein.

\section{Effects of supplementation on body composition profiles}

The weight and BMI demonstrated significant interaction effects $(\mathrm{F}(2,20)=61.14, \quad p=0.022$; $\mathrm{F}(2,20)=2.52, p=0.039$, respectively) (Table 2 ). The weight and BMI of the whey group were significantly higher than those of the placebo group at the end-test $(p<0.016)$. The body fat showed no significant difference in main or interaction effects. The muscle mass index demonstrated significant supplementation main effects $(\mathrm{F}(1,10)=12.95, p=0.005)$ and interaction effects $(F(2,20)=28.37, p=0.004)$. The whey group had a significantly elevated muscle mass compared to the placebo group at the post-test and end-test points $(p<0.016)$.

\section{Effects of supplementation on exercise performance}

In "Material and methods", we described how the distances at four time points $(3,6,9$, and $12 \mathrm{~min})$ were consecutively recorded. The running distance had time-dependent consequences, so the time main effects definitely exhibited significance at the pre-test and post-test. Table 3 shows that there was no significant supplementation main or interaction effects $(p>0.05)$ at the pre-test point, and distances in both groups at the four recording points also did not significantly differ. After 4 weeks of supplementation, the post-test showed significant supplementation main effects $(\mathrm{F}(1,10)=8.59, p=0.015)$ and interaction effects $(F(3,30)=17.67, p<0.001)$. Distances at 9 and 12 min in the whey group significantly increased compared to the placebo group $(p<0.012)$. 
Table 2. General characteristics of the body composition

\begin{tabular}{|c|c|c|c|c|c|c|c|}
\hline \multirow[t]{2}{*}{ Characteristic } & \multirow[t]{2}{*}{ Treatment } & \multirow[t]{2}{*}{ Pre-test } & \multirow[t]{2}{*}{ Post-test } & \multirow[t]{2}{*}{ End-test } & \multicolumn{3}{|l|}{$p$ values } \\
\hline & & & & & $\begin{array}{l}\text { Main effect } \\
\text { (Sup.) }\end{array}$ & $\begin{array}{l}\text { Main effect } \\
\text { (Times) }\end{array}$ & $\begin{array}{l}\text { Interaction } \\
\text { (Sup. x Times) }\end{array}$ \\
\hline \multirow[t]{2}{*}{ Weight (kg) } & Placebo & $61.6 \pm 4$ & $63.8 \pm 3$ & $60.3 \pm 5^{*}$ & 0.196 & 0.505 & 0.022 \\
\hline & Whey & $63.2 \pm 3$ & $64.2 \pm 3$ & $67.4 \pm 3^{*}$ & & & \\
\hline \multirow[t]{2}{*}{ BMI $\left(\mathrm{kg} / \mathrm{m}^{2}\right)$} & Placebo & $20.4 \pm 0.9$ & $20.6 \pm 0.6$ & $20.0 \pm 1.2^{*}$ & 0.160 & 0.643 & 0.039 \\
\hline & Whey & $20.6 \pm 0.7$ & $20.9 \pm 0.9$ & $21.6 \pm 0.8^{*}$ & & & \\
\hline \multirow[t]{2}{*}{ Body Fat (\%) } & Placebo & $11.8 \pm 2.3$ & $11.9 \pm 1.2$ & $11.5 \pm 0.4$ & 0.225 & 0.581 & 0.502 \\
\hline & Whey & $11.5 \pm 2.5$ & $10.5 \pm 2.9$ & $09.9 \pm 1.8$ & & & \\
\hline \multirow[t]{2}{*}{ SMM (kg) } & Placebo & $31.0 \pm 2.3$ & $30.1 \pm 2.5^{\star}$ & $30.3 \pm 3^{*}$ & 0.005 & 0.473 & 0.004 \\
\hline & Whey & $32.1 \pm 1.6^{a}$ & $34.3 \pm 2.4^{*}, \mathrm{~b}$ & $34.7 \pm 1^{*}, \mathrm{~b}$ & & & \\
\hline
\end{tabular}

The post-test was assessed 1 day after the marathon. The main effect of supplementation (Sup.) means the whey and placebo treatments, and the other main effect of time was the three-time point assessments (pre-test, post-test, and end-test). Data are presented as the mean \pm SD for $n=6$ in each group. The statistical analysis was a two-way ANOVA, and $p$ values of $<0.05$ were considered to significantly differ. The post hoc test was performed by a repeated Student's $t$-test between groups at the same time point, and significance $\left(^{*}\right)$ was set at an alpha level of $0.016(0.05 / 3)$. Data in the same row (within group) followed by different letters $(\mathrm{a}, \mathrm{b}$, and $\mathrm{c})$ significantly differ at $p<0.016$ $(0.05 / 3)$.

Table 3. Distance measurements obtained at 3-min intervals during the 12 -min walk/run test

\begin{tabular}{|c|c|c|c|c|c|c|c|}
\hline Treatments & $\begin{array}{l}3 \text { min } \\
(\mathrm{m})\end{array}$ & $\begin{array}{l}6 \text { min } \\
(\mathrm{m})\end{array}$ & $\begin{array}{l}9 \text { min } \\
(\mathrm{m})\end{array}$ & $\begin{array}{l}12 \text { min } \\
(\mathrm{m})\end{array}$ & $\begin{array}{l}\text { Main effect }{ }^{2} \\
\text { (Sup.) }\end{array}$ & $\begin{array}{l}\text { Main effect } \\
\text { (Times) }\end{array}$ & $\begin{array}{l}\text { Interaction } \\
\text { (Sup. } \times \text { Times) }\end{array}$ \\
\hline \multicolumn{8}{|l|}{ Pre-test } \\
\hline Placebo & $946 \pm 10$ & $1873 \pm 36$ & $2810 \pm 85$ & $3730 \pm 62$ & 0.846 & $<0.001$ & 0.985 \\
\hline Whey & $943 \pm 17$ & $1879 \pm 32$ & $2800 \pm 64$ & $3742 \pm 68$ & & & \\
\hline \multicolumn{8}{|l|}{ Post-test 1} \\
\hline Placebo & $935 \pm 28$ & $1878 \pm 69$ & $2725 \pm 760$ & $3566 \pm 112$ & 0.015 & $<0.001$ & $<0.001$ \\
\hline Whey & $953 \pm 50$ & $1889 \pm 10$ & $2821 \pm 29^{*}$ & $3776 \pm 58^{*}$ & & & \\
\hline
\end{tabular}

1The post-test was assessed after 4 weeks of supplementation.

${ }^{2}$ The main effect of supplementation (Sup.) means the whey and placebo treatments, and the other main effect of time was distance records at the four time points ( $3,6,9$, and $12 \mathrm{~min})$. Data are presented as the mean \pm SD for $n=6$ in each group. Statistical analysis was a two-way ANOVA, and $p$ values of $<0.05$ were considered to significantly differ. The post-hoc test was performed by a repeated Student's $t$-test between groups at the same time point, and significance $\left(^{*}\right)$ was set at an alpha level of $0.012(0.05 / 4)$.

\section{Discussions}

In the current clinical study, we found that whey protein could mitigate AST, LDH, CK, BUN, and TC levels which were elevated by a marathon in the placebo group, and AST, ALT, LDH, CK, BUN, TG, $\mathrm{TC}$, and LDL levels were also significantly lower than those in the placebo group after the marathon (post-test). After 1 week of recovery (end-test), we observed that AST, LDH, CK, BUN, and LDL were still significantly lower in the whey group compared to the placebo group (Table 1). Whey protein supplementation demonstrated functional activities in terms of physiological protection and recovery promotion. As to the body composition, whey protein supplementation significantly increased the weight compared to the placebo, via elevating the muscle mass (Table 2). The combination of physiological protection and muscle mass elevation can contribute to significant improvements in exercise performance.

In recent years, people have become interested in marathon running due to recognition of the positive effects of endurance exercise on health and physical strength. Regular/programmed exercise has beneficial effects on health maintenance, but irregular strenuous exercise can exert negative impacts on health [13]. During prolonged exercise, such as a marathon or exhaustive exercise, membrane permeability is altered and large amounts of enzymes, such as CK, LDH, AST, and ALT, can leak out which reflects muscle damage [14,15], and a high-intensity exercise challenge can cause physical and chemical tissue damage. It can cause sarcomeric damage and muscle cell necrosis [16]. Previous studies also demonstrated the functional bioactivities of whey protein on preventing exercise injuries, such as hepatic and muscular health promotion [17-19]. Muscle markers had significantly increased 1 day after the marathon [20], which is consistent with our sampling point (post-test). In the current study, we also found that first 3 weeks of whey supplementation ameliorated increased related indexes caused by completing a marathon, as they were was also significantly lower than those of the placebo group (Table 1).

A study of lipids and lipid proteins in aerobic athletes showed characteristics of low TG and LDL and high HDL-cholesterol compared to those with a sedentary lifestyle [21]. Immediately after a maximal effort in a marathon, TC will be significantly elevated [22], and cholesterol also serves as a precursor for the biosynthesis of steroid hormones including the adrenal gland hormones, cortisol and aldosterone, as well as the sex hormones, progesterone, estrogens, and testosterone, and their derivatives which help maintain physiological homeostasis [23]. In the 
current study, whey supplementation also significantly decreased TG and LDL levels compared to the placebo group even with the same aerobic exercise training. The TC level of the whey group was significantly lower than that of the placebo group at the post-test point, and TC could be more efficiently converted to related hormones which improves physiological adaptations.

Physiological fatigue results from inadequate rest, physical loading, or mental strain/pressure and is further classified as central or peripheral fatigue [24]. Peripheral fatigue can be assessed by important serum indicators such as lactate, ammonia, glucose, CK, BUN, ALT, and ALT related to exercise fatigue or injury $[25,26]$. We found that after the first 3 weeks supplementation, the whey group exhibited significantly lower AST, ALT, LDH, CK, and BUN levels after the marathon (post-test), indicating that the whey group maintained a lower peripheral fatigue status. At the recovery phase (end-point), the whey group still showed lower related indicators including AST, LDH, CK, and BUN, than the placebo group. This means that whey protein supplementation can ameliorate exercise fatigue and promote recovery.

Whey protein studies on the body composition and exercise performance are controversial. One recent study showed that whey protein supplementation for 1 week in duration in elite cyclists with strenuous training did not affect their exercise performance [27]. In a basketball player study, 8 weeks of whey protein supplementation significantly elevated the 1-repetition maximum (1 $\mathrm{RM}$ ) and agility, compared to a placebo group [28]. In our study, we found that the whey group with supplementation showed better running records as compared to self-record, and the $12 \mathrm{~min}$ run/walk test also proved that whey protein promoted a higher endurance capacity (table 3) after 4 weeks of supplementation. This is also consistent with our previous animal studies, which showed that exercise with whey protein produced higher endurance performance than the exercise-only group with 5 weeks of intensive aerobic training [12]. However, the muscle mass of the whey group significantly increased (Table 2), which was different from previous in vivo results. The programmed exercise prescriptions in subjects contained varieties of intensive aerobic training and the high-intensive interval training (HIIT) was also an important part. HIIT with whey protein for 3 weeks duration improved the maximum oxygen volume $\left(\mathrm{VO}_{2} \mathrm{max}\right)$, critical velocity, and lean body mass in a previous study [29]. This could possibly explain why the muscle mass significantly increased with whey supplementation for 5 weeks in our study. Besides, there was no significant differences between whey and placebo groups $(3336 \pm 367$ and $3171 \pm 394$ $\mathrm{kcal} /$ day, respectively) in daily caloric intake and the effects of performance and muscle mass were improved by whey supplementation and training program.

\section{Conclusions}

Whey protein is an important nutrient supplement for muscle-building applications with resistant training. In the current study, we found that whey protein can also play roles of physiological protection and performance elevation with various types of aerobic exercise. Marathons have become a popular exercise in recent years, because people recognize the positive effects of aerobic and endurance exercise on health promotion and physiological maintenance. An increasing number of amateur runners are participating in recreational 10and/or $21-\mathrm{km}$ races, because the physiological demand is lower than for full or ultramarathons [30]. Therefore, the high quality protein, whey protein, could be a potential option for nutrient supplementation with aerobic type exercises.

\section{Acknowledgments}

We appreciate the efforts of the anonymous referees and their useful comments and suggestions for improving the manuscript. We also thank Chamberlin Daniel Pickren for the careful reading of the manuscript. The corresponding author acknowledges the National Science Council of Taiwan (grant no. NSC102-2628-H179-001-MY2) for financial support of this study.

\section{Authors' contributions}

Chi-Chang Huang, Yong-Cheng Chang, and Nai-Wen Kan designed the experiments. Wen-Ching Huang, Yong-Cheng Chang, Yi-Ming Chen, Yi-Ju Hsu and Chi-Chang Huang carried out the supplement preparation, laboratory experiments, and field trial. Wen-Ching Huang, Sheng-Shih Chen, and Nai-Wen Kan analyzed the data, interpreted the results, prepared figures, and wrote the manuscript. Sheng-Shih Chen and Nai-Wen Kan contributed reagents, materials, and analysis platforms.

\section{Competing Interests}

The authors have declared that no competing interest exists.

\section{References}

1. Madureira AR, Tavares T, Gomes AM, Pintado ME, Malcata FX. Invited review: physiological properties of bioactive peptides obtained from whey proteins. J Dairy Sci. 2010;93:437-55. 
2. Hulmi JJ, Lockwood CM, Stout JR. Effect of protein/essential amino acids and resistance training on skeletal muscle hypertrophy: A case for whey protein. Nutr Metab. (Lond) 2010;7:51.

3. Garlick PJ. The role of leucine in the regulation of protein metabolism. J Nutr. 2005;135:1553-56.

4. Appuhamy JA, Knoebel NA, Nayananjalie WA, Escobar J, Hanigan MD. Isoleucine and leucine independently regulate mTOR signaling and protein synthesis in MAC-T cells and bovine mammary tissue slices. J Nutr. 2012;142:484-91.

5. Farup J, Rahbek SK, Vendelbo MH, Matzon A, Hindhede J, Bejder A, et al. Whey protein hydrolysate augments tendon and muscle hypertrophy independent of resistance exercise contraction mode. Scand J Med Sci Sports. 2014;24:788-98.

6. Morton RW, McGlory C, Phillips SM. Nutritional interventions to augment resistance training-induced skeletal muscle hypertrophy. Front Physiol. 2015;6:245.

7. Huang CC, Huang WC, Yang SC, Chan CC, Lin WT. Ganoderma tsugae hepatoprotection against exhaustive exercise-induced liver injury in rats. Molecules. 2013;18:1741-54

8. Li D, Wang X, Liu B, Liu Y, Zeng Z, Lu L, et al. Exercises in hot and humid environment caused liver injury in a rat model. PLoS One. 2014;9:e111741.

9. Chiu YH, Hou SK, How CK, Li LH, Kao WF, Yang CC, et al. Influence of a $100-\mathrm{km}$ ultra-marathon on hepatitis B carrier runners. Int J Sports Med. 2013;34:841-5.

10. Zhao XN, Liang JL, Chen HB, Liang YE, Guo HZ, Su ZR, et al. Anti-Fatigue and Antioxidant Activity of the Polysaccharides Isolated from Millettiae speciosae Champ. Leguminosae. Nutrients. 2015;7:8657-69.

11. Lopez HL, Ziegenfuss TN, Park J. Evaluation of the Effects of BioCell Collagen, a Novel Cartilage Extract, on Connective Tissue Support and Functional Recovery From Exercise. Integr Med (Encinitas). 2015;14:30-8.

12. Chen WC, Huang WC, Chiu CC, Chang YK, Huang CC. Whey protein improves exercise performance and biochemical profiles in trained mice. Med Sci Sports Exerc. 2014;46:1517-24.

13. Packer L, Cadenas E, Davies KJ. Free radicals and exercise: an introduction. Free Radic Biol Med. 2008;44:123-25

14. Brancaccio P, Maffulli N, Limongelli FM. Creatine kinase monitoring in sport medicine. Br Med Bull. 2007;81-82:209-30.

15. Huang KC, Wu WT, Yang FL, Chiu YH, Peng TC, Hsu BG, et al. Effects of freshwater clam extract supplementation on time to exhaustion, muscle damage, pro/anti-inflammatory cytokines, and liver injury in rats after exhaustive exercise. Molecules. 2013;18:3825-38.

16. Warren GL, Ingalls CP, Lowe DA, Armstrong RB. Excitation-contraction uncoupling: major role in contraction-induced muscle injury. Exerc Sport Sci Rev. 2001;29:82-87.

17. Tarango-Hernández S, Alarcón-Rojo AD, Robles-Sánchez M, Gutiérrez-Méndez N, Rodríguez-Figueroa JC. Short communication: Potential of Fresco-style cheese whey as a source of protein fractions with antioxidant and angiotensin-I-converting enzyme inhibitory activities. J Dairy Sci. 2015;98:7635-9.

18. Abdel-Wahhab KG, Fawzi H, Mannaa FA. Paraoxonase-1 (PON1) inhibition by tienilic acid produces hepatic injury: Antioxidant protection by fennel extract and whey protein concentrate. Pathophysiology. 2016;23:19-25.

19. van Dijk M, Dijk FJ, Bunschoten A, van Dartel DA, van Norren K, Walrand S, et al. Improved muscle function and quality after diet intervention with leucine-enriched whey and antioxidants in antioxidant deficient aged mice. Oncotarget. 2016;7:17338-55.

20. Santos RV, Bassit RA, Caperuto EC, Costa Rosa LF. The effect of creatine supplementation upon inflammatory and muscle soreness markers after a $30 \mathrm{~km}$ race. Life Sci. 2004;75:1917-24.

21. Cardoso Saldaña GC, Hernández de León S, Zamora González J, Posadas Romero C. Lipid and lipoprotein levels in athletes in different sports disciplines. Arch Inst Cardiol Mex. 1995;65:229-35.

22. Sgouraki E, Tsopanakis A, Kioussis A, Tsopanakis C. Acute effects of short duration maximal endurance exercise on lipid, phospholipid and lipoprotein levels. J Sports Med Phys Fitness. 2004;44:444-50.

23. Hanukoglu, I. Steroidogenic enzymes: structure, function, and role in regulation of steroid hormone biosynthesis. J Steroid Biochem Mol Biol. 1992;43:779-804

24. Zwarts MJ, Bleijenberg G, van Engelen BG. Clinical neurophysiology of fatigue. Clin Neurophysiol. 2008;119:2-10.

25. Lin CI, Huang WC, Chen WC, Kan NW, Wei L, Chiu YS, et al. Effect of whole-body vibration training on body composition, exercise performance and biochemical responses in middle-aged mice. Metabolism. 2015;64:1146-56.

26. Antunes HK, Leite GS, Lee KS, Barreto AT, Santos RV, Souza Hde S, et al. Exercise deprivation increases negative mood in exercise-addicted subjects and modifies their biochemical markers. Physiol Behav. 2016;156:182-90.

27. Hansen M, Bangsbo J, Jensen J, Krause-Jensen M, Bibby BM, Sollie O, et al. Protein intake during training sessions has no effect on performance and recovery during a strenuous training camp for elite cyclists. J Int Soc Sports Nutr. 2016;13:9.

28. Taylor LW, Wilborn C, Roberts MD, White A, Dugan K. Eight weeks of preand postexercise whey protein supplementation increases lean body mass and improves performance in Division III collegiate female basketball players. Appl Physiol Nutr Metab. 2016;41:249-54.
29. Smith $\mathrm{AE}$ Fukuda $\mathrm{DH}$ Kendall $\mathrm{KL}$, Stout JR. The effects of a pre-workoutsupplement containing caffeine, creatine, and amino acids during three weeks of high-intensity exercise on aerobic and anaerobic performance. J Int Soc Sports Nutr. 2010;7:10.

30. Lippi G, Salvagno GL, Danese E, Tarperi C, La Torre A, Guidi GC, et al. The baseline serum value of a-amylase is a significant predictor of distance running performance. Clin Chem Lab Med. 2015;53:469-76. 